\title{
Cabozantinib as a Second-Line Agent in Advanced Hepatocellular Carcinoma
}

Masatoshi Kudo

Department of Gastroenterology and Hepatology, Kindai University Faculty of Medicine,

Osaka-Sayama, Japan

Prof. M. Kudo

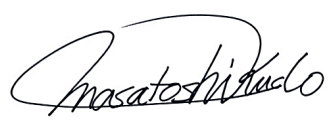

Editor Liver Cancer

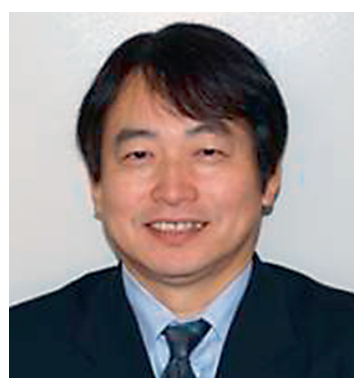

\section{Introduction}

The results of the phase III CELESTIAL trial of cabozantinib were presented by Prof. Ghassan Abou-Alfa at the ASCO Gastrointestinal Cancer Symposium held in San Francisco from January 18 to 20, 2018 [1]. Although most of the previous clinical trials of second-line agents, except regorafenib [2], failed [3-8], the CELESTIAL trial yielded positive results in line with most expectations and produced a fourth molecular-targeted drug option for hepatocellular carcinoma (HCC). Based on this trial, cabozantinib can be added as a second-line option to the first-line drugs sorafenib $[9,10]$ and lenvatinib $[11]$ and the second-line drug regorafenib [2] (Table 1).

\section{Phase II Trial of Cabozantinib}

The structural formula of cabozantinib is relatively similar to that of regorafenib $[12,13]$ (Fig. 1), although the kinase inhibitory activity $\left(\mathrm{IC}_{50}\right)$ of cabozantinib is different. Cabozantinib was originally identified as a dual inhibitor of VEGFR-2 and c-MET [14, 15], whereas current data suggest that it is a more potent inhibitor of MET, AXL, RET, FLT3, and TIE-2 than regorafenib (Tables 2, 3). VEGF, MET, and AXL are involved in tumor proliferation and angiogenesis, and MET and AXL are involved in the acquisition of resistance to antiangiogenic drugs [14-18]. VEGF, MET, or AXL expression is considered a poor prognostic factor [14-18]. 
Table 1. Phase III clinical trials of advanced stage HCC

\begin{tabular}{|c|c|c|c|c|c|c|c|}
\hline & & Design & Trial name & Result & Presentation & Publication & First author \\
\hline \multirow[t]{10}{*}{ First line } & $\begin{array}{l}1 \\
2\end{array}$ & $\begin{array}{l}\text { Sorafenib vs. sunitinib } \\
\text { Sorafenib } \pm \text { erlotinib }\end{array}$ & $\begin{array}{l}\text { SUN1170 } \\
\text { SEARCH }\end{array}$ & $\begin{array}{l}\text { Negative } \\
\text { Negative }\end{array}$ & $\begin{array}{l}\text { ASCO } 2011 \\
\text { ESMO } 2012\end{array}$ & $\begin{array}{l}\text { J Clin Oncol } 2013 \\
\text { J Clin Oncol } 2015\end{array}$ & $\begin{array}{l}\text { Cheng } \\
\text { Zhu }\end{array}$ \\
\hline & 3 & Sorafenib vs. brivanib & BRISK-FL & Negative & AASLD 2012 & J Clin Oncol 2013 & Johnson \\
\hline & 4 & Sorafenib vs. linifanib & LiGHT & Negative & ASCO-GI 2013 & J Clin Oncol 2015 & Cainap \\
\hline & 5 & Sorafenib \pm doxorubicin & CALGB 80802 & Negative & ASCO-GI 2016 & & \\
\hline & 6 & Sorafenib \pm HAIC & SILIUS & Negative & EASL 2016 & $\begin{array}{l}\text { Lancet Gastroenterol } \\
\text { Hepatol } 2018\end{array}$ & Kudo \\
\hline & 7 & Sorafenib \pm Y90 & SARAH & Negative & EASL 2017 & Lancet Oncol 2017 & Vilgrain \\
\hline & 8 & Sorafenib \pm Y90 & SIRveNIB & Negative & ASCO 2017 & J Clin Oncol 2018 & Chow \\
\hline & 9 & Sorafenib vs. lenvatinib & REFLECT & Positive & ASCO 2017 & Lancet 2018 & Kudo \\
\hline & 10 & Sorafenib vs. nivolumab & CheckMate-459 & Ongoing & & & \\
\hline & 11 & $\begin{array}{l}\text { Sorafenib vs. durvalumab }+ \\
\text { tremelimumab vs. durvalumab }\end{array}$ & HIMALAYA & Ongoing & & & \\
\hline \multirow[t]{12}{*}{ Second line } & 1 & Brivanib vs. placebo & BRISK-PS & Negative & EASL 2012 & J Clin Oncol 2013 & Llovet \\
\hline & 2 & Everolimus vs. placebo & EVOLVE-1 & Negative & ASCO-GI 2014 & JAMA 2014 & Zhu \\
\hline & 3 & Ramucirumab vs. placebo & REACH & Negative & ESMO 2014 & Lancet Oncol 2015 & Zhu \\
\hline & 4 & S-1 vs. placebo & S-CUBE & Negative & ASCO 2015 & $\begin{array}{l}\text { Lancet Gastroenterol } \\
\text { Hepatol } 2017\end{array}$ & Kudo \\
\hline & 5 & ADI-PEG 20 vs. placebo & NA & Negative & ASCO 2016 & & \\
\hline & 6 & Regorafenib vs. placebo & RESORCE & Positive & WCGC 2016 & Lancet 2017 & Bruix \\
\hline & 7 & Tivantinib vs. placebo & METIV-HCC & Negative & ASCO 2017 & & \\
\hline & 8 & Tivantinib vs. placebo & JET-HCC & Negative & ESMO 2017 & & \\
\hline & 9 & DT vs. placebo & ReLive & Negative & ILCA 2017 & & \\
\hline & 10 & Cabozantinib vs. placebo & CELESTIAL & Positive & ASCO-GI 2018 & & Ghassan \\
\hline & 11 & Ramucirumab vs. placebo & REACH-2 & Ongoing & & & \\
\hline & 12 & Pembrolizumab vs. placebo & KEYNOTE-240 & Ongoing & & & \\
\hline
\end{tabular}

Red, positive trials; blue, ongoing trials; black, negative trials. HCC, hepatocellular carcinoma; HAIC, hepatic arterial infusion chemotherapy; DT, doxorubicinloaded nanoparticles.

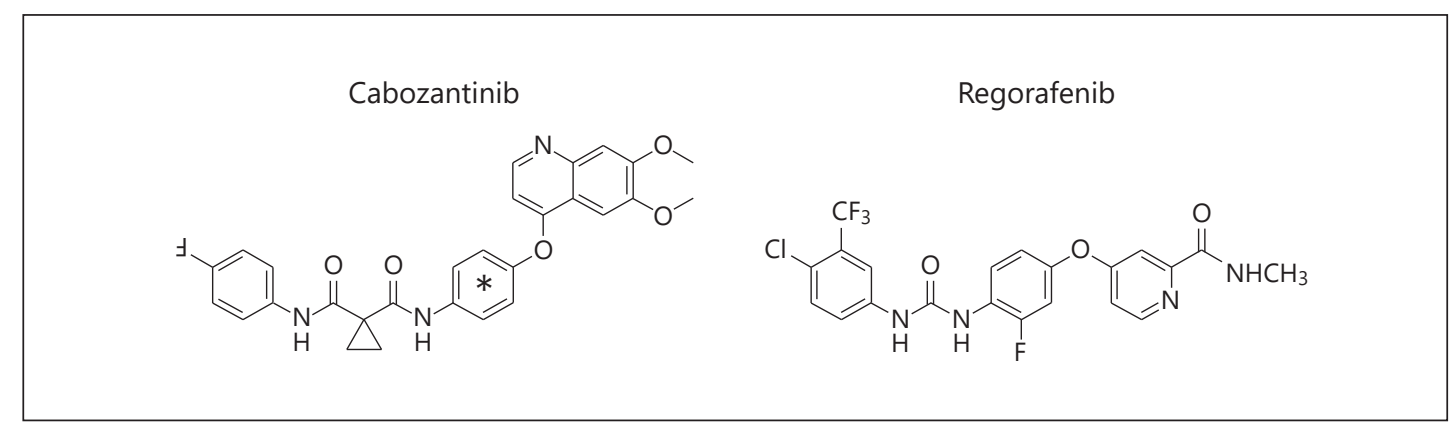

Fig. 1. Chemical structure of cabozantinib and regorafenib.

A waterfall plot from the phase II trial showed tumor shrinkage in a large proportion of patients. Progression-free survival (PFS) was 4.2 months in sorafenib-naïve patients and 5.5 months in sorafenib-pretreated patients, and overall survival (OS) was 11.5 months [15] (Table 4). The overall response rate (ORR) was $5 \%$, the disease control rate was $81 \%$, and PFS was 5.2 months (Table 4). Considering that some patients in the cabozantinib trial received first-line therapy, the results were not very good compared with the results of the phase II trial of regorafenib [19] (Table 4). Cabozantinib was also associated with a higher incidence of adverse events (AEs) than regorafenib (Table 5). 


\section{Liver \\ Cancer}

Table 2. Cabozantinib targets VEGFR-2, c-MET, RET, AXL, TIE2, and FLT3

Table 3. Mode of action: cabozantinib and regorafenib

Table 4. Comparison of efficacy (phase II): cabozantinib and regorafenib

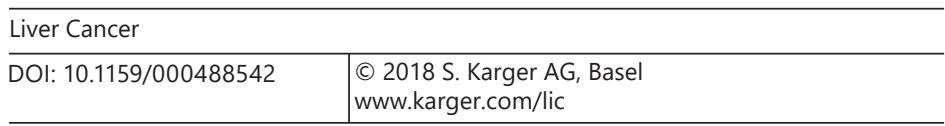

Kudo: Cabozantinib as a Second-Line Agent in Advanced Hepatocellular Carcinoma

\begin{tabular}{lr}
\hline Biochemical activity & $\mathrm{IC}_{50}, \mathrm{nmol} / \mathrm{L}$ \\
\hline VEGFR-2 & 14 \\
c-MET & 2 \\
c-KIT & 752 \\
RET & 8 \\
AXL & 8 \\
TIE2 & 13 \\
FLT3 & 21 \\
PDGFR- $\beta$ & 575 \\
\hline
\end{tabular}

\begin{tabular}{lcc}
\hline $\begin{array}{l}\text { Biochemical } \\
\text { activity }\end{array}$ & $\begin{array}{c}\text { Cabozantinib } \\
\mathrm{IC}_{50}, \mathrm{nM}\end{array}$ & $\begin{array}{l}\text { Regorafenib } \\
\mathrm{IC}_{50} \pm \mathrm{SD}, \mathrm{nM}\end{array}$ \\
\hline MET & 2 & $\mathrm{NA}$ \\
AXL & 8 & $\mathrm{NA}$ \\
VEGFR-2 & 14 & $4.2 \pm 1.6$ \\
VEGFR-1 & $\mathrm{NA}$ & $13 \pm 0.4$ \\
VEGFR-3 & $\mathrm{NA}$ & $46 \pm 10$ \\
BRAF & $\mathrm{NA}$ & $28 \pm 10$ \\
TIE-2 & 13 & $311 \pm 46$ \\
PDGFR- $\beta$ & 575 & $22 \pm 3$ \\
FGFR1 & $\mathrm{NA}$ & $202 \pm 18$ \\
c-Kit & 752 & $7 \pm 2$ \\
RET & 8 & $1.5 \pm 0.7$ \\
Flt-3 & 21 & $\mathrm{NA}$ \\
\hline \multicolumn{2}{c}{ Modified from $[12,13]}$. \\
\hline
\end{tabular}

\begin{tabular}{lcc}
\hline & Cabozantinib $(n=41)$ & Regorafenib $(n=36)$ \\
\hline ORR, \% & 5 & 3 \\
DCR, \% & 81 & 72 \\
PFS/TTP, months & $5.2(5.5)$ & 4.3 \\
OS, months & 11.5 & 13.8 \\
\hline
\end{tabular}

ORR, objective response rate; DCR, disease control rate; PFS, progression-free survival; TTP, time to progression; OS, overall survival.

\section{Phase III CELESTIAL Trial}

In light of these results, a phase III trial of cabozantinib was conducted (Fig. 2). The trial design was not as sophisticated as that of the RESORCE trial $[2,20]$. For example, vascular invasion and/or extrahepatic spread was included as a stratification factor, which may result in an unfavorable imbalance regarding patients with vascular invasion. In fact, this unfavorable imbalance was present in the BRISK-PS trial and resulted in negative results [3]. The BRISK-PS trial did not include alpha-fetoprotein as a stratification factor, which caused an unfavorable balance against the trial drug similar to that seen in the REFLECT trial [11]. The RESORCE trial led to the inclusion of vascular invasion as an independent stratification factor 
Table 5. Cabozantinib vs. regorafenib: comparison of adverse events (phase II)

\begin{tabular}{|c|c|c|c|c|}
\hline & \multicolumn{2}{|c|}{ Cabozantinib $(n=41)$} & \multicolumn{2}{|c|}{ Regorafenib $(n=36)$} \\
\hline & all grades & grade $3-4$ & all grades & grade $3-4$ \\
\hline Hand foot skin reaction & 56 & 15 & 53 & 14 \\
\hline Fatigue & 56 & 2 & 53 & 17 \\
\hline Hypertension & 24 & 10 & 36 & 3 \\
\hline Appetite loss & 29 & 0 & 36 & 0 \\
\hline Nausea & 37 & 2 & 33 & 0 \\
\hline Vomiting & 37 & 2 & 14 & 0 \\
\hline Diarrhea & 63 & 20 & 53 & 6 \\
\hline Body weight loss & 22 & 2 & 19 & 0 \\
\hline Constipation & 22 & 0 & 25 & 0 \\
\hline
\end{tabular}

Values are shown as percentages. Modified from [15, 19].

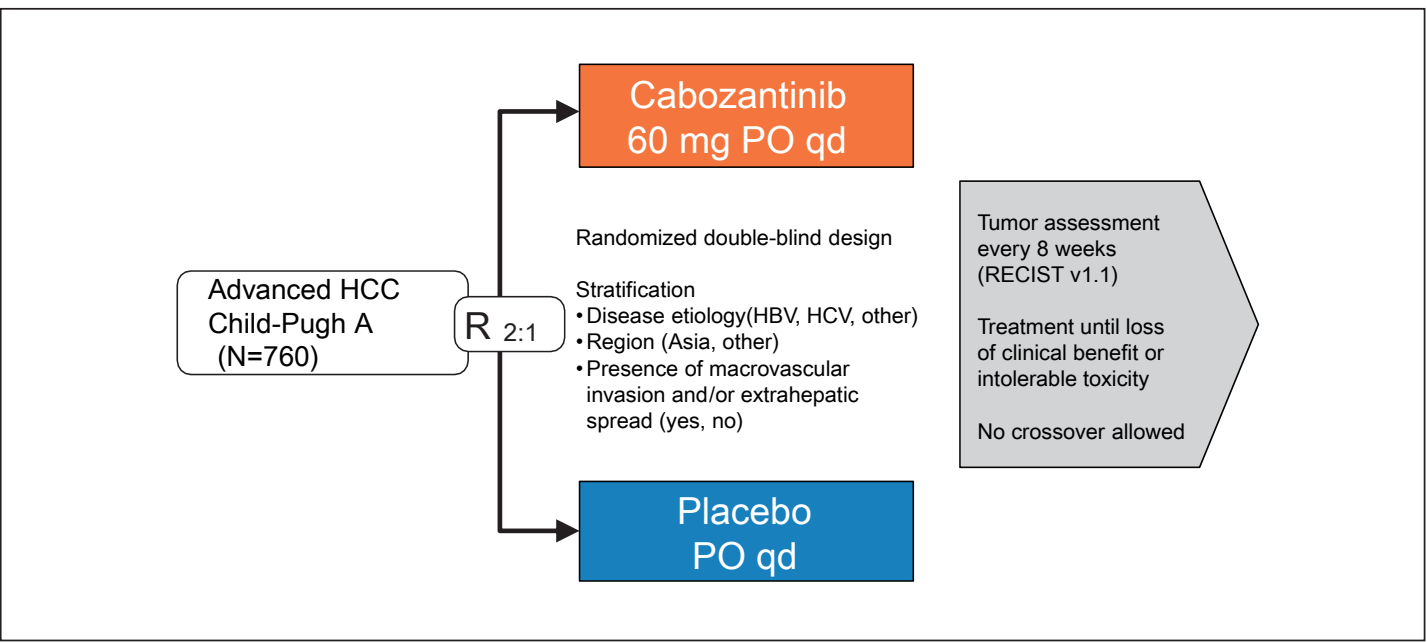

Fig. 2. CELESTIAL trial: study design.

and alpha-fetoprotein as a stratification factor in the design of trials of second-line drugs [21]. However, the CELESTIAL trial had a conventional design with few strategic elements (Table 6) and did not even exclude sorafenib-intolerant patients as in the RESORCE trial [2, 20,21]. The only inclusion criteria regarding prior treatment were (a) prior sorafenib treatment, (b) progression following at least 1 prior systemic treatment for HCC, and (c) up to 2 prior systemic regimens for advanced HCC; the exact number of sorafenib-intolerant patients enrolled remains unclear.

Between September 2013 and September 2017, the trial enrolled 773 patients with unresectable HCC showing disease progression after at least 1 prior systemic chemotherapy regimen containing sorafenib. The second interim analysis performed in January 2016 demonstrated the superiority of cabozantinib in terms of the primary endpoint of OS. There was an imbalance in baseline patient characteristics between the cabozantinib and placebo groups caused by the failure to include vascular invasion and extrahepatic spread as independent stratification factors; namely, the rate of vascular invasion was only $27 \%$ in the cabozantinib group compared with $34 \%$ in the placebo group, which favored the cabozantinib 
Table 6. Phase III clinical trials: advanced stage second line versus placebo

\begin{tabular}{|c|c|c|c|c|c|c|c|c|}
\hline & $\begin{array}{l}\text { BRISK-PS } \\
\text { Brivanib }\end{array}$ & $\begin{array}{l}\text { EVOLVE-1 } \\
\text { Everolimus }\end{array}$ & $\begin{array}{l}\text { REACH } \\
\text { Ramucirumab }\end{array}$ & $\begin{array}{l}\text { S-CUBE } \\
\text { S1 }\end{array}$ & $\begin{array}{l}\text { RESORCE } \\
\text { Regorafenib }\end{array}$ & $\begin{array}{l}\text { METIV-HVV } \\
\text { Tivantinib }\end{array}$ & $\begin{array}{l}\text { KEYNOTE-240 } \\
\text { Pembrolizumab }\end{array}$ & $\begin{array}{l}\text { CELESTIAL } \\
\text { Cabozantinib }\end{array}$ \\
\hline $\begin{array}{l}\text { Intolerance of } \\
\text { sorafenib, \% }\end{array}$ & $12-13$ & $18.5-20$ & $13-15$ & $30.6-33.8$ & 0 & $17-21$ & - & $\mathrm{N} / \mathrm{A}$ \\
\hline $\begin{array}{l}\text { Stratification } \\
\text { factor }\end{array}$ & $\begin{array}{l}\text { Reason for } \\
\text { sorafenib } \\
\text { discontinuation } \\
\text { ECOG-PS score } \\
\text { Extrahepatic } \\
\text { spread, and/or } \\
\text { vascular } \\
\text { invasion }\end{array}$ & $\begin{array}{l}\text { Region } \\
\text { MVI }\end{array}$ & $\begin{array}{l}\text { Region } \\
\text { Cause of } \\
\text { liver disease } \\
\text { (HBV, HCV, } \\
\text { other) }\end{array}$ & $\begin{array}{l}\text { Medical } \\
\text { institutions } \\
\text { Extrahepatic } \\
\text { metastasis } \\
\text { and/or } \\
\text { vascular } \\
\text { invasion }\end{array}$ & $\begin{array}{l}\text { Region } \\
\text { ECOG-PS } \\
\text { score } \\
\text { Extrahepatic } \\
\text { spread } \\
\text { Vascular } \\
\text { invasion } \\
\text { AFP }\end{array}$ & $\begin{array}{l}\text { Extrahepatic } \\
\text { spread } \\
\text { Vascular } \\
\text { invasion } \\
\text { AFP }\end{array}$ & $\begin{array}{l}\text { Region } \\
\text { Vascular } \\
\text { invasion } \\
\text { AFP }\end{array}$ & $\begin{array}{l}\text { Region } \\
\text { Disease } \\
\text { etiology (HBV, } \\
\text { HCV, other) } \\
\text { Extrahepatic } \\
\text { metastasis } \\
\text { and/or } \\
\text { vascular } \\
\text { invasion }\end{array}$ \\
\hline
\end{tabular}

After the BRISK-PS trial, where there was an imbalance of AFP and MVI in the testing arm, AFP and MVI started to be included as independent stratification factors in most trials, but not in the CELESTIAL trial. Modified from [1-6]. AFP, alpha-fetoprotein; MVI, macrovascular invasion.

Table 7. Baseline characteristics

\begin{tabular}{lll}
\hline & Cabozantinib $(n=470)$ & Placebo $(n=237)$ \\
\hline Median (range) age, years & $64(22-86)$ & $64(24-86)$ \\
Male, \% & 81 & 85 \\
ECOG performance status 0/1, \% & $52 / 48$ & $55 / 45$ \\
AFP $\geq 400$ ng/mL, \% & 41 & 43 \\
Enrollment region, \% & & \\
$\quad$ Asia/Europe/North America/Pacific & $25 / 49 / 23 / 3$ & $25 / 46 / 25 / 5$ \\
Etiology of HCC, \% & & 38 \\
$\quad 38 V$ & 22 & 22 \\
$\quad$ HCV & 40 & 41 \\
$\quad$ Other & 79 & 77 \\
Extrahepatic spread of disease, \% & 27 & 34 \\
Macrovascular invasion, \% & 85 & 84 \\
Extrahepatic spread and/or macrovascular invasion, \% & & \\
\hline
\end{tabular}

Asia: Hong Kong, South Korea, Singapore, Taiwan; Pacific: Australia and New Zealand. Cited from [1]. AFP, alpha-fetoprotein; HCC, hepatocellular carcinoma.

group (Table 7). This resulted in significantly better OS in the cabozantinib group (10.2 months, 95\% CI: 9.1-12.0) than in the placebo group (8.2 months, 95\% CI: 9.1-12.0) and consequently in a positive result for the clinical trial. PFS, the secondary endpoint, was also better in the cabozantinib group (5.2 months, 95\% CI: 4.0-5.5) than in the placebo group (1.9 months, 95\% CI: 1.9-1.9) (Table 8). PFS of 1.9 months in the placebo arm in the CELESTIAL trial was similar to that of 1.5 months in the placebo arm in the RESORCE trial (Fig. 3). Moreover, ORR was superior in the cabozantinib group ( 4 vs. $0.4 \% ; p=0.0086$ ) (Table 9). Post-trial treatment was performed in a comparably low proportion of patients in the cabozantinib and placebo groups ( $25 \mathrm{vs.} 30 \%$ ), demonstrating the poor condition of the patient population. In summary, although the relative number of sorafenib-intolerant patients in the trial was not reported, it can be inferred from the trial results that the proportion was relatively low (Table 10). 
Table 8. Time to event: CELESTIAL (second and third line) versus RESORCE

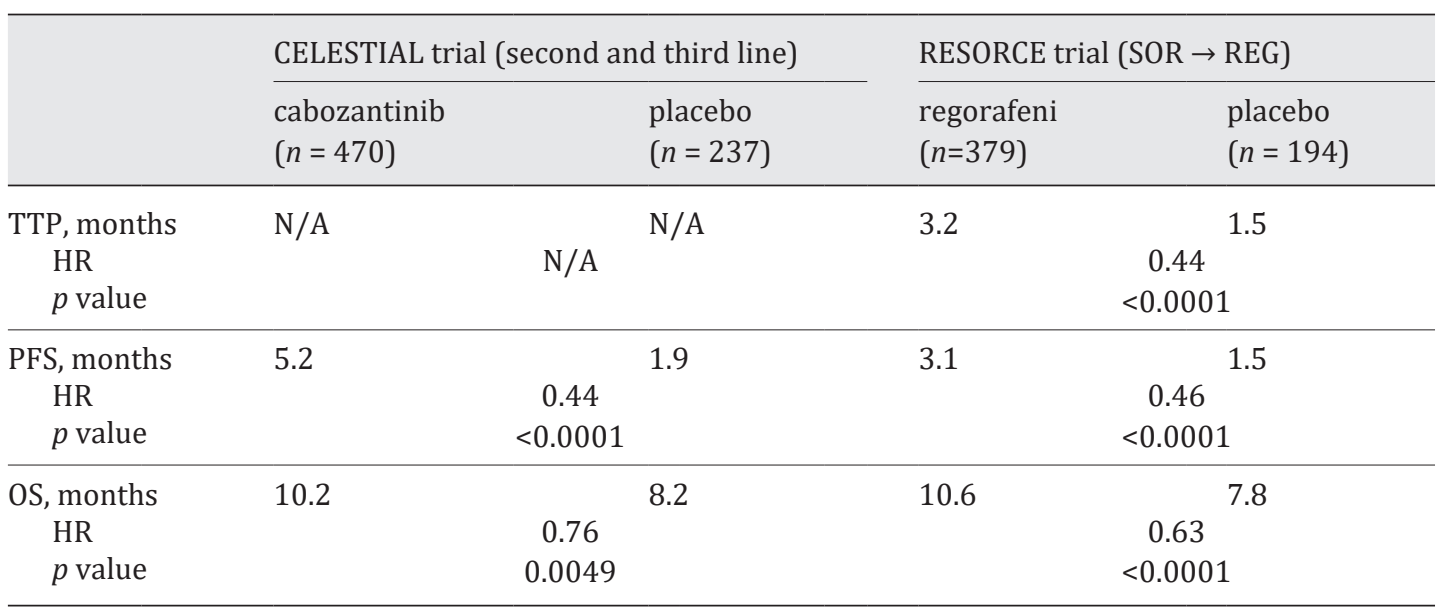

TTP, time to progression; PFS, progression-free survival; OS, overall survival. Modified from [1, 2].

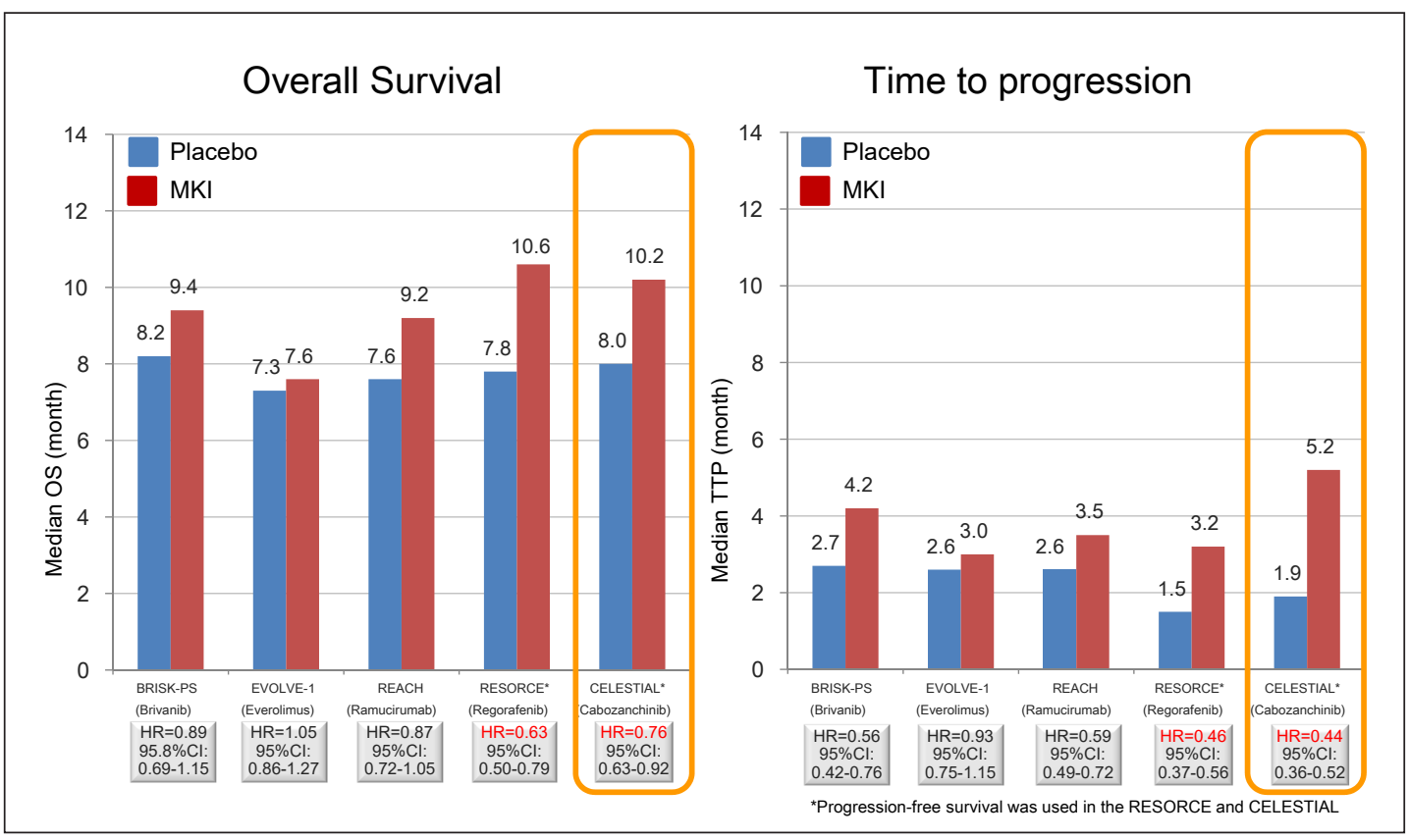

Fig. 3. Phase III trial: second line. Time to progression (TTP) was shorter in the placebo arm in the CELESTIAL trial, similar to placebo arm in the RESORCE trial, suggesting that there were fewer sorafenib-intolerant patients in the CELESTIAL trial. Anticancer activity may be higher than that of other agents, as indicated by the longer TTP. MKI, multikinase inhibitor.

\section{Comparison between Regorafenib and Cabozantinib: Efficacy and Safety}

Cabozantinib and regorafenib had comparable efficacy in terms of OS, ORR, and PFS (Tables 8,9$)$. Patients who received prior treatment with sorafenib alone showed slightly better outcomes (Table 10), which were comparable to those of regorafenib.

The duration of treatment with cabozantinib was 3.8 months, which was comparable to the 3.6 months for regorafenib and indicates acceptable tolerability, similar to that of regorafenib. 
Table 9. Tumor response: CELESTIAL vs. RESORCE

\begin{tabular}{|c|c|c|c|c|}
\hline & \multicolumn{2}{|c|}{ CELESTIAL trial } & \multicolumn{2}{|c|}{ RESORCE trial } \\
\hline & $\begin{array}{l}\text { cabozantinib } \\
(n=470)\end{array}$ & $\begin{array}{l}\text { placebo } \\
(n=237)\end{array}$ & $\begin{array}{l}\text { regorafenib } \\
(n=379)\end{array}$ & $\begin{array}{l}\text { placebo } \\
(n=194)\end{array}$ \\
\hline Response criteria & \multicolumn{2}{|c|}{ RECIST 1.1} & \multicolumn{2}{|c|}{ RECIST 1.1} \\
\hline $\begin{array}{l}\text { ORR, } \% \\
\quad p \text { value }\end{array}$ & \multicolumn{2}{|c|}{0.0086} & \multicolumn{2}{|c|}{0.02} \\
\hline $\begin{array}{l}\text { DCR, } \% \\
\quad p \text { value }\end{array}$ & \multicolumn{2}{|c|}{$\mathrm{N} / \mathrm{A}$} & \multicolumn{2}{|c|}{$<0.0001$} \\
\hline
\end{tabular}

ORR, objective response rate; DCR, disease control rate. Modified from [1, 2].

Table 10. Time to event: CELESTIAL (SOR $\rightarrow$ CAB) vs. RESORCE

\begin{tabular}{|c|c|c|c|c|}
\hline & \multicolumn{2}{|c|}{ CELESTIAL trial (SOR $\rightarrow$ CAB) } & \multicolumn{2}{|c|}{ RESORCE trial (SOR $\rightarrow$ REG) } \\
\hline & $\begin{array}{l}\text { cabozantinib } \\
(n=331)\end{array}$ & $\begin{array}{l}\text { placebo } \\
(n=164)\end{array}$ & $\begin{array}{l}\text { regorafenib } \\
(n=379)\end{array}$ & $\begin{array}{l}\text { placebo } \\
(n=194)\end{array}$ \\
\hline $\begin{array}{l}\text { TTP, months } \\
\text { HR } \\
p \text { value }\end{array}$ & $\mathrm{N} / \mathrm{A}$ & N/A & 3.2 & 1.5 \\
\hline $\begin{array}{l}\text { PFS, months } \\
\quad \text { HR } \\
p \text { value }\end{array}$ & 5.5 & 1.9 & 3.1 & 1.5 \\
\hline $\begin{array}{c}\text { OS, months } \\
\text { HR } \\
p \text { value }\end{array}$ & 11.3 & 7.2 & 10.6 & 7.8 \\
\hline
\end{tabular}

TTP, time to progression; PFS, progression-free survival; OS, overall survival. Modified from [1, 2].

Dose reduction or discontinuation because of treatment-related AEs was more common with cabozantinib than with regorafenib. Specific AEs such as palmar-plantar erythrodysesthesia, diarrhea, and asthenia were more common with cabozantinib than with regorafenib, indicating that cabozantinib may have a slightly higher toxicity than regorafenib (Table 11).

\section{Key Factors Contributing to the Success of the CELESTIAL Trial}

The following 5 factors may have contributed to the success of the CELESTIAL trial of cabozantinib despite the unsophisticated trial design compared with that of the RESORCE trial and the drug's slightly higher toxicity (Table 12).

1. Cabozantinib has a sufficiently potent antitumor activity.

2. Toxicity and tolerability were clinically acceptable.

3. An imbalance in vascular invasion favored cabozantinib. 


\section{Liver Cancer}

\begin{tabular}{l|l}
\hline Liver Cancer \\
\hline DOI: $10.1159 / 000488542$ & $\begin{array}{l}\text { C } 2018 \text { S. Karger AG, Basel } \\
\text { www.karger.com/lic }\end{array}$ \\
\hline
\end{tabular}

Table 11. Safety analysis: CELESTIAL vs. RESORCE

\begin{tabular}{lll}
\hline & Cabozantinib $(n=467)$ & Regorafenib $(n=374)$ \\
\hline Treatment duration, months & 3.8 & 3.6 \\
Dose reduction due to adverse event, \% & 62 & 48 \\
Discontinuation due to TRAE, \% & 16 & 10 \\
\hline Grade 3/4 & & \\
Any grade 3 or 4 adverse event, \% & 68 & 66 \\
Palmar-plantar erythrodysesthesia, \% & 17 & 13 \\
Fatigue, \% & 10 & 9 \\
Hypertension, \% & 16 & 15 \\
Diarrhea, \% & 10 & 3 \\
Asthenia, \% & 7 & NA \\
Bilirubin increased, \% & NA & 10 \\
AST increased, \% & 12 & 11 \\
Ascites, \% & NA & 4 \\
Anemia, \% & 4 & 5 \\
Hypophosphatemia, \% & NA & 9 \\
\hline
\end{tabular}

AST, aspartate aminotransferase; NA, not applicable. TRAE, treatment-related adverse event. NCI-CTCAE v4.03.

Table 12. CELESTIAL trial: key factors of the success
- Cabozantinib has good anticancer activity

- Acceptable toxicity and tolerability

- Imbalance of vascular invasion favoring cabozantinib

- Small number of sorafenib-intolerant patients (short time to progression in placebo)

- $\quad$ Extremely high numbers of enrolled patients ( $n=470$ vs. 379 , 362, 283, 263)

$\rightarrow$ Higher power to detect the small difference and eliminate the effect of tiny imbalance

4. The short time to progression in the placebo arm and low proportion of patients having post-trial treatment indicate low enrollment of sorafenib-intolerant patients, which was similar to no enrollment of sorafenib-intolerant patients in the RESORCE trial.

5. The sample size of 470 patients was considerably higher than that of other second-line trials and provided sufficient power to eliminate the effect of the small imbalance and detect small differences as significant (Table 13).

\section{Paradigm Shift in the Treatment Strategy for HCC}

Sorafenib was the only HCC drug available between 2007 and 2016. Between 2017 and 2018, 5 drugs, sorafenib, lenvatinib, regorafenib, cabozantinib, and nivolumab, became available. Therefore, it is necessary to establish how these drugs should be used in clinical practice (Fig. 4). Combinations of immune checkpoint inhibitors and molecular-targeted drugs or molecular-targeted drugs and established locoregional therapies [22] are particularly likely to produce a paradigm shift in the treatment of HCC. The treatment landscape for 


\section{Liver Cancer}

\begin{tabular}{l|l}
\hline Liver Cancer \\
\hline DOI: 10.1159/000488542 & $\begin{array}{l}\text { C) 2018 S. Karger AG, Basel } \\
\text { www.karger.com/lic }\end{array}$ \\
\hline
\end{tabular}

Kudo: Cabozantinib as a Second-Line Agent in Advanced Hepatocellular Carcinoma

Table 13. Phase III trials in a second line setting

\begin{tabular}{|c|c|c|c|c|c|}
\hline & $\begin{array}{l}\text { CELESTIAL } \\
\text { cabozantinib } \\
\operatorname{arm}(n=470)\end{array}$ & $\begin{array}{l}\text { RESORCE } \\
\text { regorafenib } \\
\operatorname{arm}(n=379)\end{array}$ & $\begin{array}{l}\text { BRISK-PS } \\
\text { brivanib } \\
\operatorname{arm}(n=263)\end{array}$ & $\begin{array}{l}\text { EVOLVE-1 } \\
\text { everolimus } \\
\operatorname{arm}(n=362)\end{array}$ & $\begin{array}{l}\text { REACH } \\
\text { ramucirumab } \\
\text { arm }(n=283)\end{array}$ \\
\hline Male, \% & 81 & 88 & 82 & 84 & 83 \\
\hline Median age (range), years & $64(22-86)$ & $64(19-85)$ & 64 (19-89) & $67(21-86)$ & $64(28-87)$ \\
\hline Asian race, $\%$ & 25 & 41 & 48 & 38 & 46 \\
\hline ECOG PS $0 / 1, \%$ & $52 / 48$ & $65 / 35$ & $57 / 39$ & $59 / 36$ & $56 / 44$ \\
\hline Child Pugh A, \% & NA & 98 & 92 & 98 & 98 \\
\hline BCLC stage, B/C, \% & NA & $14 / 86$ & $9 / 87$ & $14 / 87$ & $12 / 88$ \\
\hline $\mathrm{AFP} \geq 400 \mathrm{ng} / \mathrm{mL}, \%$ & 41 & 43 & $50^{\mathrm{a}}$ & $47^{\mathrm{a}}$ & 42 \\
\hline MVI, \% & 27 & 29 & 31 & 33 & 29 \\
\hline EHS, \% & 79 & 70 & 65 & 74 & 73 \\
\hline \multicolumn{6}{|l|}{ Etiology, \% } \\
\hline Alcohol & NA & 24 & 23 & 18 & - \\
\hline HBV & 38 & 38 & 39 & 25 & 35 \\
\hline HCV & 22 & 21 & 28 & 26 & 27 \\
\hline NASH & NA & 7 & - & 4 & - \\
\hline Intolerance of sorafenib, \% & - & 0 & 13 & 19 & 13 \\
\hline $\begin{array}{l}\text { Median total duration of prior sorafenib, } \\
\text { months }\end{array}$ & 5.3 & 7.8 & - & - & - \\
\hline $\begin{array}{l}\text { Median time from disease progression } \\
\text { to randomization, months }\end{array}$ & 16 & 09 & - & _ & \\
\hline
\end{tabular}

AFP, alpha-fetoprotein; MVI, macrovascular invasion; EHS, extrahepatic spread; NASH, non-alcoholic steatohepatitis. ${ }^{\text {a }} \mathrm{AFP} \geq 200 \mathrm{ng} / \mathrm{mL}$.

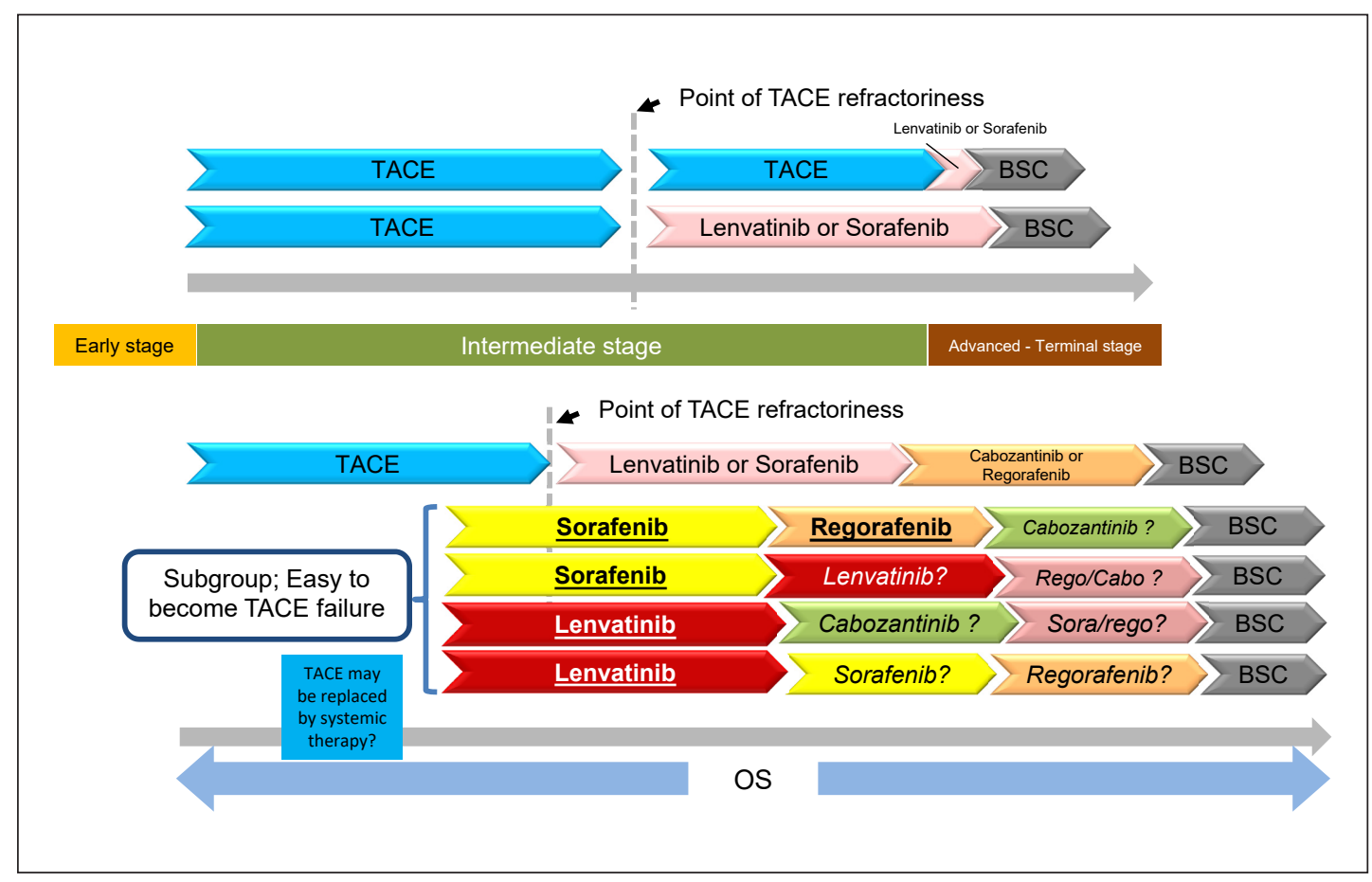

Fig. 4. New treatment landscape in HCC associated with the emergence of multiple molecular-targeted agents. Identification of the subgroup that easily develops to TACE failure/refractories may be important. BSC, best supportive care. 
HCC will soon undergo major changes as systemic therapy is integrated into the treatment for all stages, from early to intermediate to advanced, which could drastically improve the prognosis of patients with HCC.

\section{Conclusion}

The success of the clinical trial of cabozantinib increased the treatment options for HCC, and combination treatment with immunotherapy may soon improve the prognosis of patients with HCC.

\section{References}

1 Ghassan K, Abou-Alfa GK, Meyer T, Cheng AL, Anthony B, Khoueiry EI, Rimassa L, et al: Cabozantinib (C) versus placebo (P) in patients (pts) with advanced hepatocellular carcinoma (HCC) who have received prior sorafenib: results from the randomized phase III CELESTIAL trial. J Clin Oncol 2018;36(suppl 4S);abstr 207.

-2 Bruix J, Qin S, Merle P, Granito A, Huang YH, Bodoky G, Pracht M, et al: Regorafenib for patients with hepatocellular carcinoma who progressed on sorafenib treatment (RESORCE): a randomised, double-blind, placebocontrolled, phase 3 trial. Lancet 2017;389:56-66.

-3 Llovet JM, Decaens T, Raoul JL, Boucher E, Kudo M, Chang C, Kang YK, et al: Brivanib in patients with advanced hepatocellular carcinoma who were intolerant to sorafenib or for whom sorafenib failed: results from the randomized phase III BRISK-PS study. J Clin Oncol 2013;31:3509-3516.

-4 Zhu AX, Kudo M, Assenat E, Cattan S, Kang YK, Lim HY, Poon RT, et al: Effect of everolimus on survival in advanced hepatocellular carcinoma after failure of sorafenib: the EVOLVE-1 randomized clinical trial. JAMA 2014;312:57-67.

-5 Zhu AX, Park JO, Ryoo BY, Yen CJ, Poon R, Pastorelli D, Blanc JF, et al: Ramucirumab versus placebo as secondline treatment in patients with advanced hepatocellular carcinoma following first-line therapy with sorafenib (REACH): a randomised, double-blind, multicentre, phase 3 trial. Lancet Oncol 2015;16:859-870.

6 Kudo M, Moriguchi M, Numata K, Hidaka H, Tanaka H, Ikeda M, Kawazoe S, et al: S-1 versus placebo in patients with sorafenib-refractory advanced hepatocellular carcinoma (S-CUBE): a randomised, double-blind, multicentre, phase 3 trial. Lancet Gastroenterol Hepatol 2017;2:407-417.

7 Kudo M: Molecular targeted agents for hepatocellular carcinoma: current status and future perspectives. Liver Cancer 2017;6:101-112.

8 Cucchetti A, Piscaglia F, Pinna AD, Djulbegovic B, Mazzotti F, Bolondi L: Efficacy and safety of systemic therapies for advanced hepatocellular carcinoma: a network meta-analysis of phase III trials. Liver Cancer 2017; 6:337-348.

$>9$ Llovet JM, Ricci S, Mazzaferro V, Hilgard P, Gane E, Blanc JF, de Oliveira AC, et al: Sorafenib in advanced hepatocellular carcinoma. N Engl J Med 2008;359:378-390.

10 Cheng AL, Kang YK, Chen Z, Tsao CJ, Qin S, Kim JS, Luo R, et al: Efficacy and safety of sorafenib in patients in the Asia-Pacific region with advanced hepatocellular carcinoma: a phase III randomised, double-blind, placebo-controlled trial. Lancet Oncol 2009;10:25-34.

$\checkmark 11$ Kudo M, Finn RS, Qin S, Han KH, Ikeda K, Piscaglia F, Baron A, et al: Lenvatinib versus sorafenib in first-line treatment of patients with unresectable hepatocellular carcinoma: a randomised phase 3 non-inferiority trial. Lancet 2018:Epub ahead of print.

12 Lacy S, Hsu B, Miles D, Aftab D, Wang R, Nguyen L: Metabolism and disposition of cabozantinib in healthy male volunteers and pharmacologic characterization of its major metabolites. Drug Metab Dispos 2015;43:11901207.

13 Strumberg D, Schultheis B: Regorafenib for cancer. Expert Opin Investig Drugs 2012;21:879-889.

14 Yakes FM, Chen J, Tan J, Yamaguchi K, Shi Y, Yu P, Qian F, et al: Cabozantinib (XL184), a novel MET and VEGFR2 inhibitor, simultaneously suppresses metastasis, angiogenesis, and tumor growth. Mol Cancer Ther 2011;10: 2298-2308.

15 Kelley RK, Verslype C, Cohn AL, Yang TS, Su WC, Burris H, Braiteh F, et al: Cabozantinib in hepatocellular carcinoma: results of a phase 2 placebo-controlled randomized discontinuation study. Ann Oncol 2017;28: 528-534.

16 Gay CM, Balaji K, Byers LA: Giving AXL the axe: targeting AXL in human malignancy. Br J Cancer 2017;116: 415-423.

17 Zhu AX, Duda DG, Sahani DV, Jain RK: HCC and angiogenesis: possible targets and future directions. Nat Rev Clin Oncol 2011;8:292-301. 
-18 Ueki T, Fujimoto J, Suzuki T, Yamamoto H, Okamoto E: Expression of hepatocyte growth factor and its receptor, the c-met proto-oncogene, in hepatocellular carcinoma. Hepatology 1997;25:619-623.

19 Bruix J, Tak WY, Gasbarrini A, Santoro A, Colombo M, Lim HY, Mazzaferro V, et al: Regorafenib as second-line therapy for intermediate or advanced hepatocellular carcinoma: multicentre, open-label, phase II safety study. Eur J Cancer 2013;49:3412-3419.

20 Kudo M: Regorafenib as second-line systemic therapy may change the treatment strategy and management paradigm for hepatocellular carcinoma. Liver Cancer 2016;5:235-244.

21 Kudo M: A new era of systemic therapy for hepatocellular carcinoma with regorafenib and lenvatinib. Liver Cancer 2017;6:177-184.

22 Kudo M, Ueshima K, Torimura T, Tanabe N, Ikeda M, Aikata H, Izumi N, et al: Randomized, open label, multicenter, phase II trial of transcatheter arterial chemoembolization (TACE) therapy in combination with sorafenib as compared with TACE alone in patients with hepatocellular carcinoma: TACTICS trial. ASCO-GI, 2018, Abstract No 206. 